\title{
The Influence of Embedded Music on the Memorization of Mandarin Chinese
}

\author{
Tianyu $\mathrm{Chu}^{1} \&$ Kai Bao ${ }^{2}$ \\ ${ }^{1}$ EF Education First, Shanghai, China \\ ${ }^{2}$ Department of Foreign Languages and Literatures, Tsinghua University, Beijing, China \\ Correspondence: Tianyu Chu, EF Education First, Changning Rd. 1158, Changning Dist., Shanghai, China. Tel: \\ 86-136-1681-6234. E-mail: chutianyujerry@sina.com
}

Received: August 13, 2021

Accepted: September 7, 2021

Online Published: September 8, 2021

doi:10.5430/irhe.v6n3p21

URL: https://doi.org/10.5430/irhe.v6n3p21

\begin{abstract}
The purpose of this study is to determine how embedded music affects verbal memory in the language of Mandarin Chinese. For this purpose, an experiment was conducted where 40 college students were recruited as the participants. Specifically, they were first randomly allocated into four groups, namely the 'Reading Group', the 'Ambient-music Group', the 'Embedded-music Group', and the 'Finger-tapping Group'. They were then tested for verbal recall of a lyric in terms of both short-term memory and long-term memory. The results showed that the 'Ambient-music Group' scored the highest, followed by the 'Reading Group', while the 'Finger-tapping Group' ranked the third, and the 'Embedded-music Group' was at the bottom. The results that the sung version of a lyric was recalled worse than the spoken version conforms to the recent findings, as compared with traditional notions that music can facilitate the memory of language.
\end{abstract}

Keywords: music, language, memory, poem, Mandarin Chinese

\section{Introduction}

Language is believed to be a feature that uniquely belongs to human beings. Apart from that, if there is another trait that parallels language, most people would probably agree that it is music. Language and music take place in all human societies, no matter whether other respects of culture exist or not (Nettl, 2000). Despite that studies of language and music have respectively begun since long ago, the research on the relations and comparisons between them still seems to be at its early stage. Within the past decades, a handful of contributions have been made to examine the commonalities and distinctions of language and music.

Some researchers attach more weight to their differences. It is argued that music possesses greater power over emotions than ordinary speech does, while language consists of grammatical elements which are not found in music. Also, people do not speak in the way that music uses pitches and rhythms, and semantic meanings seem to take place only in language rather than in music (Patel, 2008). Moreover, evidence abounds in exemplifying that an injury in one area of the brain does not interfere with the functions of the other, i.e. aphasia and amusia (amusia is known as a deficit in recognizing, processing and memorizing pitch, which can be either congenital or acquired) occur independently (Marin \& Perry, 1999; Peretz, 2006). Those results indicated that there is not much shared by language and music at the cognitive level. On the other hand, other researchers lay more emphasis on their similarities, holding that the two fields share quite a few basic mechanisms, even though there are some specializations (Gordon et al., 2010; Calma-Roddin \& Drury, 2020; Sternin et al., 2021; Wesseldijk et al., 2021). More specifically, they share mechanisms that integrate learned sound categories, draw the regulations of rhythm and melody, form syntactic structure with basic units like words and notes, and extract the emotional meanings from acoustic information (Patel, 2008). In addition, their interfaces with memory have aroused interests from a number of researchers.

The notion that music can act as a mnemonic device to assist memorization is not new. Music generally can be divided into ambient music (there is no direct connection between language and music) and embedded music (there is direct connection between language and music). As regards ambient music, it was discovered that classical music could help ease tension, soothe sorrow and promote the storage and recall of information, a famous instance of which was music therapy (Shapiro, 1969). Also, Carruth's (1997) experiment proved that music (at least that of Mozart's) genuinely 
improved the face-name recognition of those who suffered from Alzheimer's disease. In the later phase, Larkin's (2001) research reflected that patients with dementia were able to recall better in sounds than in silence, and better with music than with noise. In a recent study, Wesseldijk et al. (2021) revealed a close relation between musical and verbal ability of 1,336 male twins. Jekiel and Malarski's (2021) study showed that musical experience served as an important factor in helping L2 English learners produce more native-like English vowels. Despite the facilitation function of ambient music for memory, the function of embedded music, which accounts for a large proportion of popular genres, is under-researched and thus unclear. In addition, most studies in the field focus on western languages, while very limited studies have examined Mandarin Chinese, one of the most widely spoken languages in the world. To fill these gaps, the present study aims to determine how embedded music affects verbal memory in the language of Mandarin Chinese.

\section{Method}

In this study, experimental method is used as the research method to test the participants' memory in different contexts. And the research will be targeting both the participants' short-term memory and long-term memory.

\subsection{Instruments and Settings}

Both the poem and the melody are created by the researchers, so that none of the participants has ever known about them, and the stimuli can be absolutely novel. The poem is an antithetic lyric in the language of Chinese (see Appendix A). It has 4 lines, with 14 characters in each line. The melody which matches the words is also illustrated on the score, and in this way the music is supposed to be embedded into language. Accordingly, a one-minute-long recording of the author's singing is created to ensure the accuracy of pitch and rhythm.

Since it has been mentioned that Mozart's music can be helpful in improving memory (Carruth, 1997), his Fantasy for Piano No.3 is selected, which is downloaded from the Internet. Besides, a plain reading version of the poem is recorded, and the duration is also one minute, which is identical to that of the melodised version. The audios are all played on a laptop. Both the singing version and the reading version are played three times, taking three minutes all together. The poem is presented in the format of PowerPoint, simultaneously with the audio. There are four slides, with one line of the poem on each slide, so that each time there is only one line revealed. In this way, participants will be more concentrated, rather than focus on the reading and neglect the audio.

There are four conditions in this experiment. In Condition A, participants are required to receive the input in a normal classroom, where there is a text of the poem and an audio of normal reading. This group is the prototype, and is named 'Reading Group'. Condition B is actually Condition A plus the variable of ambient music, i.e. those in Condition B are kept listening to ambient classical music while taking the experiment. This group is used here as a control, and is given the name 'Ambient-music Group'. In Condition C, the target condition, the subjects are asked to undergo the same process as in Condition A, except that the audio of reading is a melodised version (music is embedded in language). And they are asked to attend to both the melody and words for later recall. Accordingly, this group is referred to as 'Embedded-music Group'. Condition D serves as another control condition, where one should not only try reciting the poem, but also keep tapping his or her fingers on the desk at a steady pace. Specifically, given that there are four lines in the poem, one of the four fingers (index, middle finger, ring finger and pinky) should be kept tapping when the reading of each line goes on. 'Which finger for which line' is randomly decided by the experimenter, and the participant should memorize the sequence while taking the task. By doing so, a comparison is made between Condition $\mathrm{C}$ and Condition D to examine the effects of using two mechanisms. Accordingly, this group is called 'Finger-tapping Group'.

A normal classroom is the venue where the experiment takes place, and the surroundings are quiet.

\subsection{Participants}

In this research, a sample composed of 40 college students ( 15 male, 25 female) are selected, all of whom are Chinese native speakers. Their ages range between 19-25, with a mean of 22.3, and no one is a musician (no more than one year of formal musical training). All participants demonstrated normal optical and auditory sensitivities and reported no previous history of neurological or psychiatric illness. Although there seem to be more female subjects in the study, gender is not considered as an important variable in the research, in that there is little strong evidence suggesting that people of different sex perform distinctly in memorization. Hence, the basic conditions of the participants are similar.

\subsection{Procedures}

The 40 participants take part in the experiment separately. To begin with, the information sheet and the consent form are forwarded to the participant, and he or she is randomly distributed to one of the four conditions (ten subjects in each condition). Because of the randomness, the interference of individuals' intelligence is weakened. The participants take 
part in the experiment at different times, but their respective durations are the same. Everyone is allowed three minutes for the input, and the test which consists of four parts follows immediately.

The first part is oral reiteration, requiring the participants to repeat the poem orally. This process lasts for about one minute, and how well the words and the melody are produced is tested. The written test comes right after the previous section, wherein the participants are required to write the poem down on a test paper (three minutes allowed). This procedure is to test short-term memory. After that, a distracter task is conducted, and they are told to do a 20-minute IELTS reading test (not a real test, since it is not marked). Finally, the written test is taken again without receiving the stimuli, and their performances of long-term memory are available.

\subsection{Analysis}

The criteria for grading the written performances are two-dimensional. The first criterion is the proportion of missing words: the fewer missing words there are, the better the performance is. The second is the ratio of incorrect words. This respect is mainly concerned with word substitution, while spelling is not considered, since spelling is not related to the memory in this study. The oral responses of the words and the melody are marked through a 1-5 scale respectively (1 indicates 'very poor', 2 indicates 'poor', 3 indicates 'fair', 4 indicates 'good', and 5 indicates 'very good'). The differences in grading formats between the written and the oral test are due to the fact that oral responses are relatively more elusive, insomuch as a greater number of repetitions and modifications are involved in the process of oral recalling, while written response is more straight-forward.

When the data is collected, the performances of each group are listed. And comparisons of difference significance between $\mathrm{A}$ and $\mathrm{B}, \mathrm{A}$ and $\mathrm{C}$ and $\mathrm{A}$ and $\mathrm{D}$ in terms of both the first and the second written tests are provided, reflecting how embedded music influences the short-term memory and long-term memory of the poem.

\subsection{Predictions}

The predictions of the results are as follows. The results of the oral test (words and melody) should be in proportion with the written test results. In other words, the higher the oral results are, the higher the written results are. The melody performances should be no better than the word results, as was found in the study of Racette and Peretz (2007, p. 250), 'Melody Recall was generally less precise than word recall, whether it was sung with the lyrics or on /la/, in both musicians and non-musicians.' The results of the short-term memory should be better than those of the long-term memory, as mental representations will fade as time goes by.

The 'Ambient-music Group' is supposed to be better or at least equivalent to the 'Reading Group', while the 'Finger-tapping Group' should be no better than the prototype. The reason for such prediction is that it is mentioned in the literature that appropriate ambient classical music can boost memory (Carruth, 1997), and the 'Finger-tapping Group' involves two tasks taken, so the participants are more burdened in that condition.

The prediction for the 'Embedded-music Group' is not that definite, given this issue is still controversial. However, we are inclined to be in favour of the idea that music has positive effects on verbal memory. In the study of Ludke et al. (2013), factors like difficulty, format of recall, presentation rate and duration were all controlled, and it was found that music would help verbal recall in Hungarian, an unfamiliar language. Accordingly, the basic settings of the present study are similar to what has been suggested, with the factors above considered, except that the language is oriental and is native to the participants. Hence, it is hypothesized that the effects will be positive, and the results of Condition C will be better than the results of Condition A. Notwithstanding, even if the opposite result is engendered, it is not surprising, since there might be some other variables not controlled.

\section{Results and Discussion}

Table 1 and 2 illustrate the four groups' performances in terms of short- and long-term memory, respectively. Figure 1 shows the means of marks received by the four groups. Figure 2 and 3 present the distributions of those marks in the first and second written test, respectively.

Table 1. Comparisons between Condition A, B, C, and D in short-term memory

\begin{tabular}{cccccc}
\hline Short-term Memory & $\begin{array}{c}\text { Mean of the } \\
\text { Former }\end{array}$ & $\begin{array}{c}\text { Mean of the } \\
\text { Latter }\end{array}$ & P-Value & 5\% Sig. & $10 \%$ Sig. \\
\hline Condition A \& B & 36.5 & 39.9 & 0.297 & Insignificant & Insignificant \\
Condition A \& C & 36.5 & 29.6 & 0.03 & Significant & Significant \\
Condition A \& D & 36.5 & 32 & 0.2 & Insignificant & Insignificant \\
\hline
\end{tabular}


Table 2. Comparisons between Condition A, B, C, and D in long-term memory

\begin{tabular}{cccccc}
\hline Long-term Memory & $\begin{array}{c}\text { Mean of the } \\
\text { Former }\end{array}$ & $\begin{array}{c}\text { Mean of the } \\
\text { Latter }\end{array}$ & P-Value & 5\% Sig. & 10\% Sig. \\
\hline Condition A \& B & 35.4 & 39.6 & 0.201 & Insignificant & Insignificant \\
Condition A \& C & 35.4 & 29.4 & 0.061 & Insignificant & Significant \\
Condition A \& D & 35.4 & 31.3 & 0.277 & Insignificant & Insignificant \\
\hline
\end{tabular}

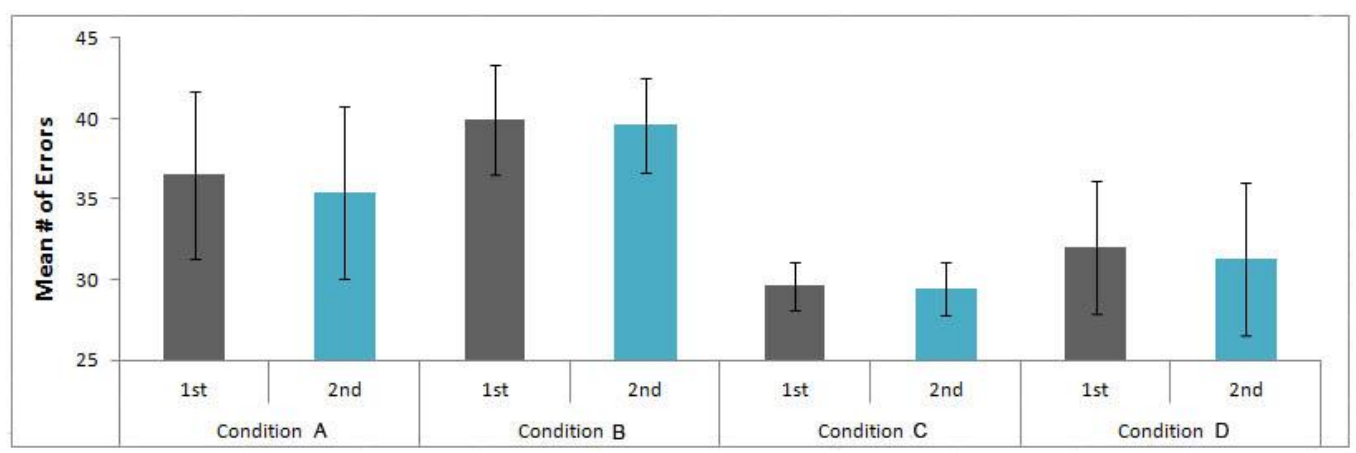

Figure 1. Means of marks received by Group A, B, C, and D

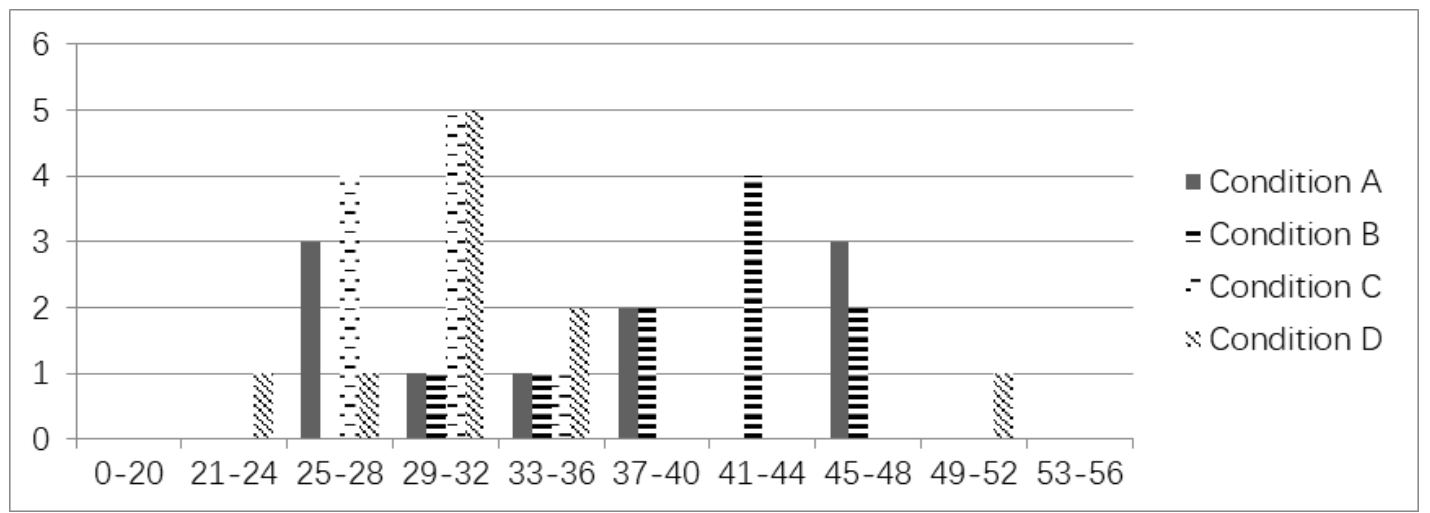

Figure 2. Distributions of marks in the first written test

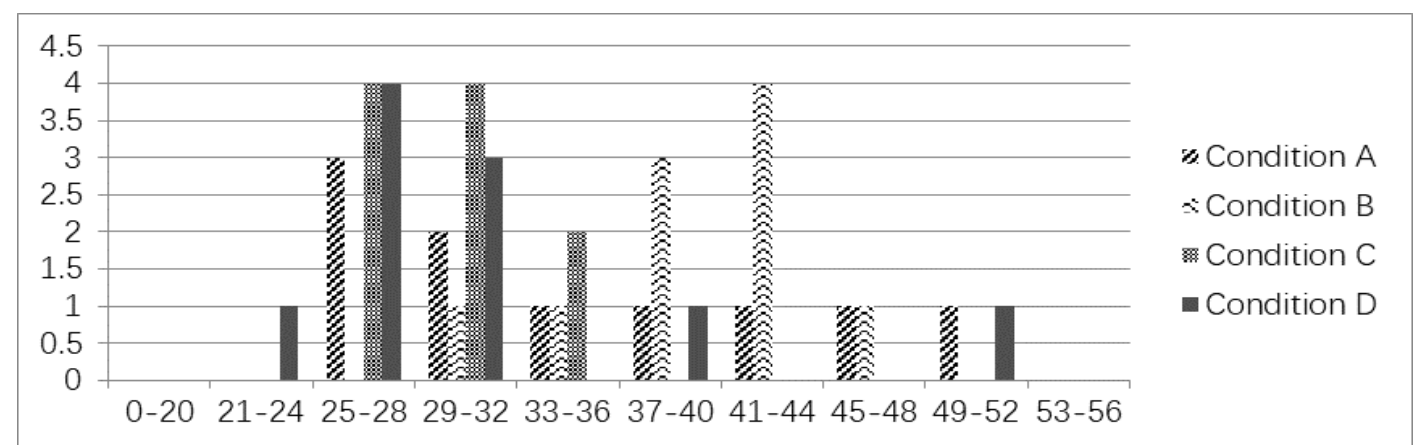

Figure 3. Distributions of marks in the second written test

The results above show that in terms of the within-group results, the oral performances are in proportion with the written performances, and the recall of words is better than that of melody. Besides, the results of the first written test are a bit better than the second, albeit with a few exceptions. With regard to the between-group results, there are similar phenomena in both the short-term and the long-term memory tests. Those in Condition B have scored higher than those 
in Condition A, but the difference is not significant. The results of Condition $\mathrm{C}$ are poorer than those of Condition $\mathrm{A}$, and the discrepancy is salient. Condition D is also worse than Condition A, but the gap is not large. In this sense, ambient music is indeed taking a little effect in improving memory, embedded music is a conspicuous obstacle of verbal recall, and finger-tapping is hindering, though not very much. The results are nearly compliant with the predictions, except that Condition A outperformed Condition C, which is unexpected and yet considered. Discussions on such discrepancy will be presented in terms of the following aspects: the limitations of the study, the language involved, different views of memory patterns, and cognitive neuroscience. The results are discussed with respect to the language involved, different views of memory patterns, and cognitive neuroscience in the following.

\subsection{The Language Involved}

Apart from the scale limitations of this study, the language involved may also be influential. Unlike the western languages used in previous studies, the language chosen here is Mandarin Chinese, which is an oriental language. There are claims that people who speak different languages have different sensitivities to music. For example, Deutsch et al. (2006) made a comparison between American musicians and Chinese musicians, and drew the following conclusion: Musicians who are tonal language speakers are more likely to have absolute pitch than their non-tonal language counterparts. Although it is not explicit enough how the differences between western languages and oriental languages affect the memory performances, it may act as an influential factor.

Moreover, unlike the study of Ludke et al. (2013) where the language of Hungarian serves as an alien language, the language of Mandarin Chinese in this experiment is native to the participants. It is suggested by Yalch (1991) that when dealing with an unfamiliar language, it is phonetic aspects that are mainly concerned. However, when coping with one's native language, more semantic factors will emerge. In this sense, more attention will be paid to the words rather than the melody, and the music in turn may act as a distracter, leading to the poorer results of Condition C in this study.

\subsection{Different Views of Memory Patterns}

Human beings normally do not memorize things as individual units, but as chunks. As an example, Attneave and Olson (1971) found that people could effortlessly sing a familiar song beginning with any key, which manifested that they did not memorize music through precise pitches or durations, but through patterns and relationships. This is because the interior hierarchical structure remains the same, regardless of the surface changes. Similarly, to memorize the sentence 'John invited Mary for dinner, but Mary said she had something else to do', for instance, people usually refer to the logical relations for memorization rather than solely words, in that changing the ordering of the words randomly will result in nonsense 'invited dinner Mary for John, something she but do else said had Mary to'.

Apart from the syntactic similarities, rhythmical overlap, as has been discussed, may also take effect in influencing the recall of the melodised poem. And it was even maintained that rhythm is the most supportive element of a musical presentation of linguistic materials in the native language (Purnell-Webb \& Speelman, 2008; Stahl et al., 2011), although it was later revised to be an influential factor instead of the most supportive element (Ludke, 2013).

There are two views on how the memorizations of music and language interact, namely the 'integrated memory view' and the 'separate memory view'. And these two views assume different ways of encoding and recalling. According to the 'integrated memory view', words and melody are aligned in songs, whereby speech and musical sounds are bound at multiple levels of processing, and are synthesized into a unitary representation (Serafine et al., 1984; Serafine et al., 1986). Once integrated, even a part of the song's representation can reinstate the whole, which means singing the melody can help recall the words, and reading the text can in turn aid in recalling the music. Accordingly, it is predicted that the text can be better recalled when sung than when read. As the 'separate memory view' goes, the linguistic and musical elements of a song are independent in both perception and recall (Peretz et al., 2004). In the experiments of Racette and Peretz (2007), music was found to be cumbering rather than facilitating verbal memory, in both musicians and non-musicians, and in both encoding and recalling processes. Also, it was suggested that at the early stages of learning a new song, music and language are memorized separately, which will make singing a dual task, leading to the unsatisfactory results of the 'Embedded-music Group'. Recent studies, as well as the results in this study, provide supports for 'separate memory view', but more evidence should be collected to clarify the issue.

\subsection{Cognitive Neuroscience}

Why embedded music worsens the verbal memory can be further expounded with theories of neuroscience. It was raised by Patel (2003) that the overlap of language and music in syntactic processing could be deemed as an overlap in the neural areas where resources for integrating complex syntax were provided. This concept is called 'Shared Syntactic Integration Resource Hypothesis'. The hypothesis is that language and music have an overlap in the resource networks, so that when both linguistic and musical tasks are being taken, the shared neural resources will be scattered, 
incurring extra efforts. This notion is not contradictory to the results of the 'Ambient-music Group', because although there is music in Condition B, no extra memory task is incurred. Instead, the background classical music can soothe the participants, and render the performances slightly higher.

By contrast, the 'Finger-tapping Group' introduces another story. In Condition D of the experiment, participants are required to remember the sequence of finger-tapping. This process consumes neural resources as well (imagine it is called physical resource), but it is not supposed that finger-tapping and music processing share the same resources. So when the two tasks are taken together, the participants will not be so stressed as those in the 'Embedded-music Group', and this interpretation conforms to the results found in this research (although the 'Finger-tapping Group' did not do as well as the prototype did, it surpassed the 'Embedded-music Group'). Accordingly, their relationship is demonstrated in the following figure, which is a mimic of the previous one.

In spite of the above interpretation, there is other evidence from cognitive neuroscience, suggesting that language and music integrate at an early stage of neural processing. And even if attention is paid to the text, the melody still affects the processing of the stimuli (Sammler et al., 2010). This claim is against some concepts aforesaid, which indicates that more evidence should be gained before consensus can be reached.

In summary, the conundrum of 'whether melody can enhance the recall of language or not' is essentially a question of how to weigh the benefits brought by music and the drawbacks begot. On the one hand, music may integrate with language and improve memory. On the other hand, music can be an extra burden, and harm the response. It seems that the latter effect is more prominent at early stages, while the former effect is more likely to be achieved in the long run, though the time span is hard to define. Since there are contradictory claims on this issue, the relationship between language and music may still remain a mystery.

\section{Conclusion}

In this study, 40 college students were recruited for the experiment. They were randomly allocated into 4 groups, namely the 'Reading Group', the 'Ambient-music Group', the 'Embedded-music Group' and the 'Finger-tapping Group', and they were tested for verbal recall in terms of both short-term memory and long-term memory. The result was that the 'Ambient-music Group' scored the highest, who were followed by the 'Reading Group', while the 'Finger-tapping Group' ranked the 3rd and the 'Embedded-music Group' was in the bottom. And the gap between the spoken version and the sung version is significant, which is out of expectation. This discrepancy leads to an introspection into the experimental design, as well as a discussion of the notions from different schools: the 'integrated memory view' versus the 'separate memory view'. It seems that agreement still remains to be achieved on the role that music plays in the recalling process, in that too many variables are to be controlled.

Overall, this study fills the research gap by exploring how embedded music affects verbal memory in the language of Mandarin Chinese. In addition, the study opens a path for future research, including investigating more details in the processes of encoding, rehearsal and retrieval, applying other methods such as fMRI or MEG to exploring the neural mechanisms in more depth, and seeking educational implications, etc. Apart from its significance, this study also has two limitations: First, there are only 10 participants in each condition, and the participants are only college students; Second, although the subjects are randomly allocated to each group, the individuals' capabilities can be very different. These limitations may influence the reliability of the results.

In the end, it is of interest to mention that when musicians are to learn a song, they will spontaneously learn the words and the melody separately before synthesizing them (Ginsborg, 2002). This might be the best practical way to combine language with music in the mind. And it is predicted that the advantages of singing over speaking will reveal, as long as the practicing time is long enough (Peretz et al., 2004). Besides, it is found that adepts and beginners perform similarly, if not much practice is given, which means every healthy individual can learn to sing (except those who suffer from amusia). Since childhood, people have been exercising to utilize a common auditory-vocal mode for learning both language and music (Merker, 2004). Such vocal learning mode is witnessed among parrots, whales and bats, but not among primates, the species closest to Homosapiens (Janik \& Slater, 1997). Again, it highlights the two sophisticated cognitive capabilities that are unique to humans, namely speech and music.

\section{References}

Attneave, F., \& Olson, R. K. (1971). Pitch as a medium: A new approach to psychophysical scaling. The American Journal of Psychology, 84(2), 147-166. https://doi.org/10.2307/1421351

Calma-Roddin, N. E., \& Drury, J. E. (2020). Music, language, and the n400: ERP interference patterns across cognitive domains. Scientific Reports, 10, 1-14. https://doi.org/10.1038/s41598-020-66732-0 
Carruth, E. (1997). The effects of singing and the spaced retrieval technique on improving face-name recognition in nursing home residents with memory loss. Journal of Music Therapy, 34, 165-186. https://doi.org/10.1093/jmt/34.3.165

Deutsch, D., Henthorn, T., Marvin, E., \& Xu, H. S. (2006). Absolute pitch among American and Chinese conservatory students: Prevalence differences, and evidence for a speech-related critical period. Journal of the Acoustical Society of America, 119, 719-722. https://doi.org/10.1121/1.2151799

Ginsborg, J. (2002). Classical singers learning and memorising a new song: An observational study. Psychology of Music, 30, 58-101. https://doi.org/10.1177/0305735602301007

Gordon, R. L., Schön, D., Magne, C., Astésano, C., \& Besson, M. (2010). Words and melody are intertwined in perception of sung words: EEG and behavioral evidence. PLoS One, 5(3), e9889. https://doi.org/10.1371/journal.pone.0009889

Janik, V. M., \& Slater, P. J. B. (1997). Vocal learning in animals. Advances in the Study of Behaviour, 26, 56-99.

Jekeil, M., \& Malarsik, K. (2021). Musical hearing and musical experience in second language English vowel acquisition. Journal of Speech, Language, and Hearing Research, 64(5), 1666-1682. https://doi.org/10.1044/2021_JSLHR-19-00253

Larkin, M. (2001). Music tunes up memory in dementia patients. The Lancet, 357(9249), 47. https://doi.org/10.1016/s0140-6736(05)71549-x

Ludke, K. M., Ferreira, F., \& Overy, K. (2013). Singing can facilitate foreign language learning. Memory \& Cognition, 42(1), 41-52. https://doi.org/10.3758/s13421-013-0342-5

Marin, O. S. M., \& Perry, D. W. (1999). Neurological aspects of music perception and performance. In D. Deutsch (Ed.), The psychology of music (pp. 653-724). San Diego, CA: Academic Press. https://doi.org/10.1016/b978-0-12-213562-0.50019-x

Merker, B. (2004). Vocal learning for song: Key constraint on the path to language. Unpublished manuscript.

Nettl, B. (2000). An ethnomusicologist contemplates universals in musical sound and musical culture. In N. L. Wallin, B. Merker, \& S. Brown (Eds.), The Origins of Music (pp. 463-472). Cambridge, MA: MIT Press. https://doi.org/10.7551/mitpress/5190.003.0032

Patel, A. D. (2003). Language, music, syntax, and the brain. Nature Neuroscience, 6, 674-681.

Patel, A. D. (2008). Music, language and the brain. Oxford: Oxford University Press.

Peretz, I. (2006). The nature of music from a biological perspective. Cognition, 100(1), 1-32. https://doi.org/10.1016/j.cognition.2005.11.004

Peretz, I., Radeau, M., \& Arguin, M. (2004). Two-way interactions between music and language: Evidence from priming recognition of tune and lyrics in familiar songs. Memory \& Cognition, 32, 142-152. https://doi.org/10.3758/bf03195827

Purnell-Webb, P., \& Speelam, C. (2008). Effects of music on memory of text. Perceptual and Motor Skills, 106, 958-962. https://doi.org/10.2466/pms.106.3.927-957

Racette, A., \& Peretz, I. (2007). Learning lyrics: To sing or not to sing?. Memory and Cognition, 35(2), 242-253. https://doi.org/10.3758/bf03193445

Sammler, D., Baird, A., Valabregue, R., Clement, S., Dupont, S., Belin, P., \& Samson, S. (2010). The relationship of lyrics and tunes in the processing of unfamiliar songs: An fMRI adaptation study. Journal of Neuroscience, 10, 3572-3578. https://doi.org/10.1523/jneurosci.2751-09.2010

Serafine, M. L., Crowder, R. G., \& Repp, B. H. (1984). Integration of melody and text in memory for songs. Cognition, 16, 285-303. https://doi.org/10.1016/0010-0277(84)90031-3

Serafine, M. L., Davidson, J., Crowder, R. G., \& Repp, B. H. (1986). On the nature of melody-text integration in memory for songs. Journal of Memory \& Language, 25, 123-135.

Shapiro, A. (1969). A pilot program in music therapy with residents of a home for the aged. The Gerontologist, 9(2), 128-133.

Stahl, B., Kotz, S. A., Henseler, I., Turner, R., \& Geyer, S. (2011). Rhyme in disguise: Why singing may not hold the key to recovery from aphasia. Brain, 134, 3083-3093. https://doi.org/10.1093/brain/awr240 
Sternin, A., Mcgarry, L. M., Owen, A. M., \& Grahn, J. A. (2021). The effect of familiarity on neural representations of music and language. Journal of Cognitive Neuroscience, 1-17. https://doi.org/10.1162/jocn_a_01737

Wesseldijk, L. W., Gordon, R. L., Mosing, M. A., \& Ullén, F. (2021). Music and verbal ability-A twin study of genetic and environmental associations. Psychology of Aesthetics, Creativity, and the Arts. Advance online publication. https://doi.org/10.1037/aca0000401

Yalch, R. F. (1991). Memory in a jingle jungle: Music as a mnemonic device in communicating advertising slogans. Journal of Applied Psychology, 76(2), 268-275. https://doi.org/10.1037/0021-9010.76.2.268

\section{Appendix A. Ambedded Music Used by the Study}
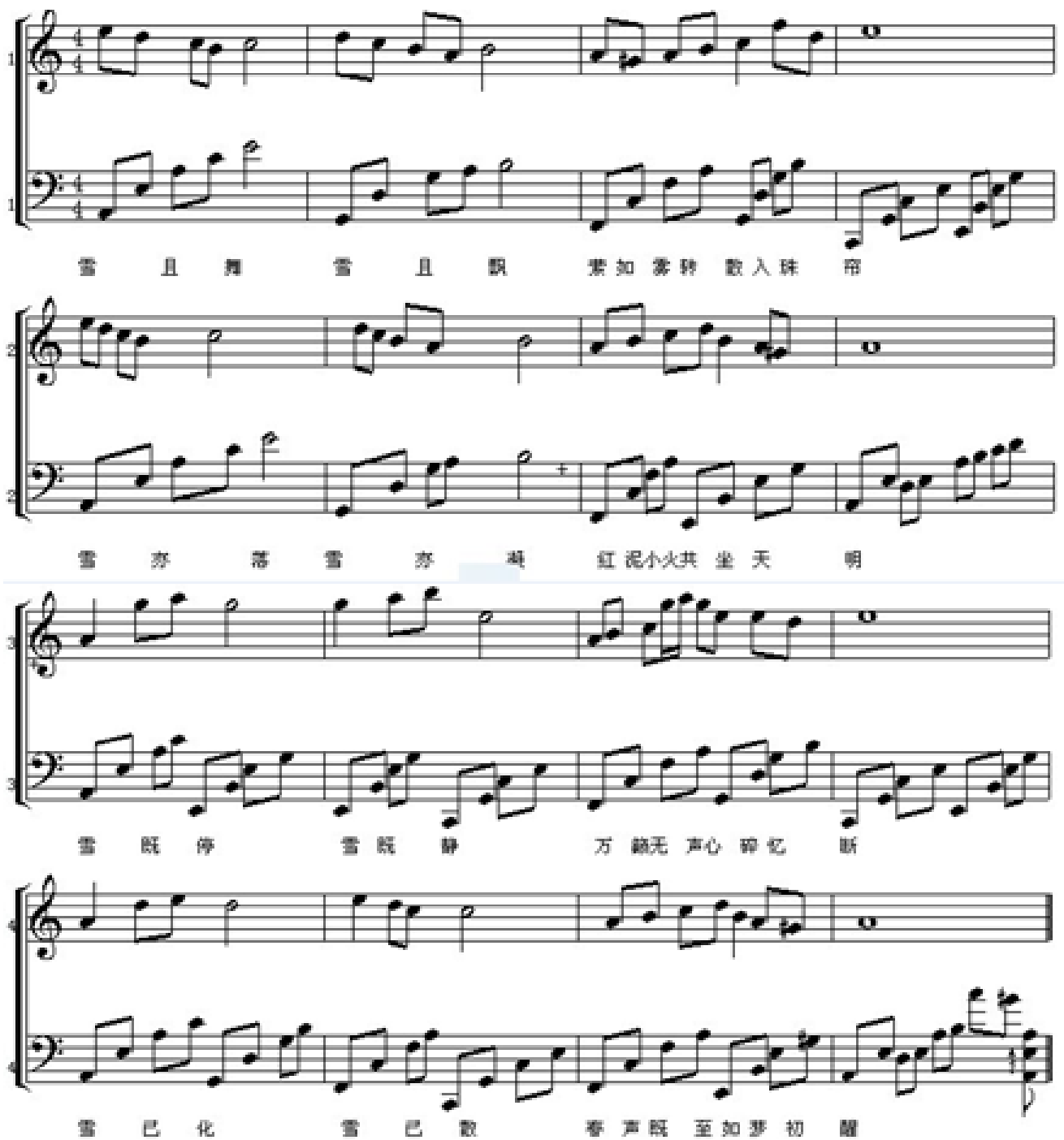

\section{Copyrights}

Copyright for this article is retained by the author(s), with first publication rights granted to the journal.

This is an open-access article distributed under the terms and conditions of the Creative Commons Attribution license (http://creativecommons.org/licenses/by/4.0/). 